\title{
Point of View in Narrative
}

\author{
Suhair Al-Alami \\ Al Ghurair University, Dubai, UAE
}

\begin{abstract}
Point of view in narrative is a focal angle of seeing, hearing, smelling, and sensing the story's settings, characters, and events. Researchers within the fields of language, linguistics and literature, assert that there are three main types of narrator: first-person, second-person, and third-person. The current paper depicts the three types, highlighting each in terms of aim, use, and potential for narrative effectiveness. Linking the paper to narrative stylistics, aspects and markers of point of view such as locative expression, thought and speech presentation, mind style, dis-narration, and modality are discussed. To examine point of view in narrative through discussing areas of relevance to the topic, the paper sheds light on socio-pragmatic and cognitive dimensions within narrative contexts. Finally, the paper concludes with a number of essential factors for shaping the construct of effective point of view in narrative.
\end{abstract}

Index Terms - fiction, first-person narrator, narrative stylistics, point of view, second-person narrator, thirdperson narrator

\section{INTRODUCTION}

This paper seeks to highlight point of view within narrative contexts, pinpointing a number of points in relation to main types of narrator, narrative stylistics, and socio-pragmatic and cognitive dimensions. Speaking in general terms, point of view can refer to two things: a point of view in arguments or nonfiction texts is an opinion, the way one judges, considers or values an issue. Considered from a narrative angle, on the other hand, a point of view is the narrator's position in the description of a story's events.

Part two of the current paper presents point of view as defined by scholars within the fields of English language, linguistics and literature. To offer a comprehensive idea about the main types of point of view, part three describes the three main types of narrator, reflecting on each with respect to aim, use, and so on. Part four offers the reader brief, yet adequate information about an area of study which is highly related to point of view: stylistics. Relating point of view to narrative stylistics, part five discusses essential aspects and markers of point of view such as modality and mind style. Next, part six portrays socio-pragmatic and cognitive dimensions within narrative contexts. Last but not least, part seven concludes with recommendations for language specialists to consider whilst narrating a story.

\section{What Does PoINT OF VIEW ENTAIL?}

Point of view can refer to two things: a point of view in a discussion is an opinion; the way one judges an issue. In narrative, however, a point of view is the narrator's position in the description of characters and events. Simpson (2010, p. 294) thinks that point of view embraces the angle of narrating in fiction. Point of view is important because it filters everything in a narrative. It determines the amount of information the narrator shares with the reader. It can also influence the degree to which the reader can identify with the protagonist (Al-Alami, 2016; 2013).

Shen (2010) believes that both first-person and third-person types of narration employ different methods. For example, the pronoun 'I' can be used in first-person narration to refer to either an observer or the protagonist. Shen proceeds to emphasize that it is extremely important to gain awareness of two dichotomies relating to point of view. These are: internal point of view which embodies the viewing position inside the story versus external point of view which embodies the viewing position outside the story. Additionally, one should be able to differentiate between outside view which entails observing a character's behavior versus inside view which entails penetrating into a character's thoughts and feelings. In Simpson's opinion (2010; 1993), point of view in narrative can be as limited as that of first-person narrator, or as wide as that of third-person omniscient. Clark (2007) explains that point of view can be deployed for different purposes. Point of view can be deployed to represent an ideological framework or a visual perspective of a story. In addition, it can be deployed to describe different types of relationships within a story's contexts.

Using a story narrator is a strategy the implementation of which can be achieved in a number of ways. Morini (2011) classifies point of view in narrative into two categories: first person and third person. First-person narration is used in texts where the story is narrated by the main protagonist, or in some cases, by a minor character. Operating as a window on the events which take place in a fictional text, third-person narration can be utilized skilfully. Within third-person narration, a narrator can be internal or external, possessing either unrestricted or restricted knowledge (Durant, et al. 2000). Whereas internal third-person narration paves the way for visualizing characters' thoughts; feelings and attitudes, external third-person narration is limited to accessing characters from outside. Whatever the type, Jacobus (1989) 
emphasizes that for a story to function properly, settings; characters; and dramatic events are all required and should be conveyed effectively by means of expressive language.

Some people may confuse point of view with perspective. Short (1996, p. 256) distinguishes between what is portrayed in the fictional world, and the perspective from which it is portrayed. This distinction in viewpoint has a significant role in making the novel the most complex literary genre in terms of discourse structure. Whereas point of view focuses on the type of narrator used to tell the story, perspective reflects how the characters view and process what happens within the story. While writing a story, one may indicate his/her perspective through using all points of view to assist the reader in clearly recognizing the narrator's attitude. Logically speaking, one's perspective influences the way he/she feels about characters and situations. Within the boundaries of a story, characters' perspectives can be different; there may be three people at one event, each with a unique set of experiences.

\section{POINT OF VIEW: WHAT, Why, AND How?}

This part of the paper highlights the three types of narrator, shedding light on main points for English language specialists to consider. It should be mentioned that this part is excluded to discussing point of view within fiction contexts rather than other genres.

To start with, first-person narrator can be identified through the use of pronouns like I, me, we, and us in the narrative. Since the information is limited to what the first-person narrator says; thinks; feels; receives and perceives, factors such as reader intimacy, connection with the character's emotional state, and visualization of physical setting make the story appealing in its own ways. First-person narrator is divided into singular and plural narration. Characterized by the use of $\mathrm{I} / \mathrm{my} / \mathrm{me} / \mathrm{myself} / \mathrm{mine}$, first-person singular delineates one's experiences, seeking to ensure that the reader will and can see the world the narrator has created. There are four main kinds of first-person narrator: firstly, the protagonist. The protagonist is the main character in the story, sharing what happens whilst providing commentary. Secondly: a secondary character, this type of narrator may rely on personal experience in narrating the story. Thirdly: the observer (witness narrator), this type of narrator can neither be identified with the author nor be engaged in the story's events. To inject commentary, the witness narrator tends to use personal pronouns. Fourthly: the unreliable narrator, this type of narrator cannot be trusted to convey the story accurately as his/her information may be skewed. As if directly communicating with the reader, the first-person singular can have an effective, intimate narrative tone. On the other hand, since the first-person narrator is limited to the narrator's experience, any events taking place outside the narrator's zone may not come to the notice of the reader. The first-person singular point of view can be a wise choice for a character-driven novel. A novel with crucial characters all leading their own lives in different venues and at different times can be demanding to convey in a first-person point of view. Turning to first-person plural, determiners and pronouns such as we/us/ours/our/ourselves are used here. First-person plural can be used when a community shares some common features and/or experiences. A major advantage of this point of view is that it is comprised of more than one person, who thus can report and reflect on events more than a single person can do. However, it might be tedious especially in the constant collective presence of several people.

Identified by the use of you, second-person narrator takes its main character you, telling us who you are, what you do, and so on. This type is the least common of all the three types, since it is the hardest to utilize in stretches of discourse without the possibility of sounding slightly awkward. The narrator is the reader, which might be tricky. Second-person is used in short stories where there is less room for redundancy. It creates an intimate relationship between character and reader. This intimate bond and the novelty of voice function can be both engaging and entertaining. However, the novelty of voice may not be adequate to sustain a long narrative such as the novel.

Divided into two sub-categories: limited and omniscient, third-person point of view is characterized by the use of: he, him, himself, she, her, and herself. This type of narrator allows for more flexibility and freedom than the other types do, because it genuinely offers a more global, wider view of what happens in the story. Commenting on third-person limited, it allows the reader to sense and perceive a particular character's feelings; thoughts and attitudes. Third-person limited offers closeness to the main character being described whilst allowing readers to investigate his/her mood, mentality, thought, feeling, perception and so on. Unlike third-person limited, third-person omniscient provides much freedom, which enables the narrator to move across different generations, numerous scenarios and varied settings. It, therefore, can be seen as an effective portrayal for readers to read between and behind characters' actions and thoughts. Furthermore, it can be viewed as an appropriate tool for novelists who have complex plots, detailed descriptions, and many casts. Though thorough and promising, much freedom might lead to disturbance of focus, blur of vision, and lack of comprehension while one is reading a narrative. It would be helpful, therefore, if omniscient narrators consider each event a unique unit the details of which are described splendidly and thoroughly impressive.

To conclude, for exploring point of view to be effective, some of the major questions to address are: does the narrator sound detached, does the narrator have a clear opinion of the story, does the narrator participate in the events being narrated, does the narrator announce his/her presence openly, is the narrator of sufficient knowledge to tell the story, and do we trust the narrator's information? Obviously, without mastering point of view, one's chances of success in narrative take a nosedive. Equally important in terms of success in narrative writing are the ability to design wellrounded characters and the ability to produce a compelling plot which keeps the reader turning the pages. 


\section{STYlistics AT a GlanCE}

In its early days, stylistics was considered a method that would allow readers to analyze language. Today, however, stylistics has become a tool for enriching not only language studies, but also culture and society related research. Stylistics has a number of subfields such as narrative stylistics, cognitive stylistics, and feminist stylistics. Crawshaw (1996) points out that stylistics is an integrated field of study, including the study areas of linguistics, sociology, and psychology.

Stylistics can be defined as a thorough examination of language style, which highlights how texts are influenced by different factors such as those of intra-linguistic features (Al-Alami, 2014). Leech (2010, p. 17) defines stylistics as a 'way of using language'. While examining language style, focus should be made on main features of a specific genre or domain like corpus. Stylistics requires thorough analyses of the text to identify how specific linguistic patterns relate to meaning and effect (Semino, 2004). Explicit, sensitive and rigorous linguistic analyses provide invaluable insights into the workings of texts.

Stylistics can be used to analyze texts of different genres and forms; nevertheless, it goes without saying that the most popular area of exploration is that of literature (Busse and McIntyre, 2010; Simpson, 2004). Cook (2003) mentions that literary stylistics has proved to be effective in the English as a foreign language classroom. It relates language use of certain patterns to the impact a specific pattern may have upon the reader. Literary stylistics is usually concerned with three aspects of a literary text; namely, its appropriate deviation from the conventions and norms of everyday language use, its skillful manipulation of language patterns, and its effective selection of vocabulary items.

\section{NARRATIVE STYLISTICS: ASPECTS AND MARKERS}

\section{A. Deixis, Verba Sentiendi, and Locative Expressions}

Stylistics involves examination of individual literary texts or extracts, to relate specific linguistic choices to potential meanings and effects. Examined from a stylistics point of view, markers of point of view can be located in certain linguistic indicators of the narrative. A description of these markers include, amongst others, categories such as 'deixis': pointing words (these versus those) whose function is to attach a narrator to a particular context (Short, 1996), 'verba sentiendi': words which represent feelings, perceptions and thoughts of narrators and characters alike (Uspensky, 1973), and 'locative expressions': phrases which refer to locations and directions indicating the spatial position of the fiction's reflector (Fowler, 1986).

\section{B. Thought and Speech Presentation}

Presentation of thought and speech is an important aspect of the narrative style. Kvantaliani (2014) states that free direct speech has its significance in terms of dramatizing characters' utterances. It enables the reader to clearly distinguish between reporting of events and reporting of speech. Free indirect speech, by contrast, provides the effects of vividness and immediacy which promote the reader's involvement in the narrative. Free indirect speech is different from other speech presentation categories due to the author's increased control of conversations, which thus allows the author to guide the reader's sympathy towards certain characters. As far as thought presentation in narrative is concerned, presenting a character's thoughts indicates the use of an omniscient narrator. Kvantaliani (2014) is of the opinion that utilizing direct categories of thought presentation like free direct thought and direct thought may hold a different value from that of the corresponding speech presentation.

Simpson (2010) argues that portrayal of a character's discourse by a narrator has a considerable impact on the perspective of narration used in the story. An influential technique to be considered is free indirect discourse: an expression which subsumes free indirect thought and speech indirect thought variants. Free indirect discourse can be seen as in-between direct and indirect discourse, depicting features of both. Of interest to narrative stylistics are the effects and images of narrators and characters talking simultaneously. Vandelanotte (2004, p. 492) stresses that in direct thought or speech, a 'verbatim representation' of the original utterances has to be maintained. In indirect thought or speech, meaning of the original utterances has to be maintained through using words other than the ones used in the original utterances (Semino, 2004; Gross, 1993).

Murphy (2007, p. 28) proposes using the term 'monitored speech' to refer to indirect speech. Semino and Short (2004), on the other hand, reveal that free indirect speech is the least frequent category of speech presentation. Moreover, free indirect speech is considered more complex than other forms because it is comprised of indirect and direct features whether grammatical, lexical, or deictic markers of subjectivity. According to Leech and Short (1981), the use of direct speech and free direct speech yields an imaginary scene of characters interacting in the presence of readers. What is more, free indirect speech distances the reader from the character, whereas free indirect thought portrays the opposite scenario; it places the reader in the character's consciousness. Free indirect thought is employed extensively in fictional texts. A number of fiction writers exploit it successfully to arouse the reader's interest in the story's world.

C. Mind Style 
In Semino's opinion (2002), mind style refers to a person's distinctive linguistic presentation of his/her mental self. Mind style is a contextual demonstration of a character's views of the world. It demonstrates consistent structural options in order to initiate an impression of a world view. Fowler (1977, p. 105) asserts that the consistently restricted nature of mind style is necessary since selection of grammar, syntax, and vocabulary restricts the story to the reflector's perspective. Mind style is not an easy concept to grasp; it might be confused with point of view. It is related to it, but it is not the same.

\section{Dis-narration}

Prince (1988, p. 2) considers dis-narration as a gap in the development of a story which can yet be comprehended and realized explicitly or inferably from a lacuna in the chronology. Not all narrative acts need to be related as readers can still infer a story's coherence from absences in the text. Hardy (2005) addresses dis-narration through highlighting narrative gaps. Instead of focusing on non-narrated areas such as negation and ellipsis, Hardy (2005; 2003) examines narrower examples in narratives the propositions, participants, or events of which are noticeably absent. Mention of the notion of gapping should not be made without mention of the counterfactual concept which refers to a dis-narrated alternative sequence that affects the evaluation of story elements. Because counterfactuals pave the way for adopting attitudinal positions in respect of realized and unrealized story events, counterfactuals should be seen as an essential marker of evaluative stance in fiction (Harding, 2007).

\section{E. Modality}

Modality is a traditional marker which makes it possible for speakers to reflect their attitudes and beliefs through what they narrate. Emphasizing that the styles of literature genres can be partly defined by recurrent and specific configurations of modality, Simpson (2010, p. 295) claims that the genre of horror fiction foregrounds certain modal structures to do with knowledge and perception. Additionally, markers of epistemic modality engender a special kind of narrative viewpoint that is not found, to the same extent, in other types of writing. Palmer (2003, p.7) delineates modality as deontic, dynamic, and epistemic. Deontic refers to the circumstances and conditions which are external to the subject of the sentence, dynamic refers to the control which is internal to the subject, and epistemic refers to the specific attitudes to status of the proposition.

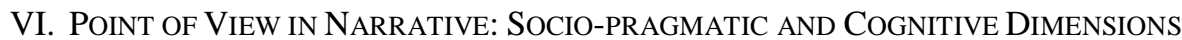

McIntyre (2004, p. 157) recommends that future research should focus on the 'fluid quality of point of view within a linguistic framework', to investigate how readers move from a viewpoint to another viewpoint in a narrative. With readers moving from a viewpoint to another in mind, Simpson (2010, p. 302) proposes that one's perception of what makes point of view is open to discussion and re-discussion, since the paradigms we use for text interpretation function differently across different eras. Much work remains within the field of stylistics if we are to reach a coherent explanation of diachronic shifts in interpretation. Simpson (2010) concludes that the way one perceives creativity is influenced by socio-pragmatic matrices through which readers interact with narratives, and that such socio-pragmatic matrices should be subsumed under stylistic analysis in relation to point of view.

Short and Candlin (1989, p. 9) suggest that the prompt, impetus, and testing ground are based on language and literature classrooms. An essential outcome of the cognition 'turn' in stylistics exemplifies psychologists' work on text interpretation. Reflecting on research studies within the scope of the current part, Egidi and Gerric (2006) investigated the way readers responded to narrative characters' aims, examining how readers identified with characters' aims the more the aims were narrated. Rapp and Gerrig (2006) explored how readers distinguished between what they referred to as moral outcome on the one hand, and the narrative outcome preferred by a character on the other. Based on these two studies amongst others, a question to raise within this context should center around the extent to which a reflector of fiction would invite empathy from readers towards preferred outcomes. Another question to address should aim to explore the extent to which use of point of view may influence readers' identification with specific kinds of outcomes in narratives.

To objectively investigate varied issues within socio-pragmatic and cognitive stylistics, synthesis between psychological studies of readers' responses to narratives and stylistic approaches to point of view would be beneficial in that research findings within one area will supplement the other area. A key point of stylistics in this regard is that it reflects a systematic account of readers' responses to narrative viewpoints. While psychological research is sophisticated when considering experimental design, narrative structure is more rudimentary. Having these considerations in mind, a number of researchers such as Simpson (2010) and (Zyngier et al, 2008) advocate the idea that combining empirical testing techniques with stylistic analysis will lead to designing a thoroughly developed model of point of view in narrative stylistics.

\section{CONCLUSION}

Seeking to offer a transparent idea about point of view in narrative, the current paper presents some definitions which have been proposed and approved by a number of scholars within the fields of English language, linguistics, and literature. As discussed in this paper, the main types of narrator are: first-person, second-person, and third-person. In 
first-person, the character is in the story, describing his/her experiences to the reader with no intrusion. This type is popular in fiction. Second-person point of view is told whilst using the pronoun you. This type, however, is not commonly used in fiction. Third-person is divided into third-person limited and third-person omniscient. In third-person limited, the story is about 'he' or 'she'. The narrator is outside of the story, reflecting and reporting on the experiences of the main character. In third-person omniscient, the story is still about 'he' or 'she', but the narrator has access to each and every character's thoughts, feelings and experiences. Whatever the type, point of view in narrative should reveal which character's eyes, if any, the reader is looking through at any given moment, how much access to a character's feelings and thoughts the reader is offered, and how closely a character's internal and external speech resembles his/her own way of thinking, feeling, and communicating.

A highly related area to studies on point of view is stylistics. The current paper, therefore, sheds light on stylistics as a field of study. As explained earlier, stylistics is an art of exploring and analyzing texts in terms of linguistic features, literary devices, discourse markers, overall organization, and the like. To further explain areas of relevance to point of view, the current paper discusses aspects and markers of narrative stylistics, and socio-pragmatic and cognitive dimensions.

In conclusion, there is no best point of view in narrative to ever utilize. An effective point of view in narrative depends on a number of factors one of which is the form of writing, which in some cases, may necessitate the use of a certain type of point of view over others. Third-person narrator, for instance, can function effectively in creative written pieces where the narrator wants to tell the story without intruding into the plot. Moreover, an effective point of view is derived from the narrator's aim; mentality and vision, not to mention the story's main elements such as character; plot; and setting which also play an important role in determining the most appropriate point of view to adopt. On a final note, what should remain as significant factors shaping the construct of effective point of view in narrative are transparency of narration, integrity of reflection, authenticity of tone, clarity of presentation, adequacy of detail, impact of communication, significance of speech, exquisiteness of style, and impression of expression.

\section{REFERENCES}

[1] Al-Alami, S. (2016). The Power of Short Stories, Novellas and Novels in Today's World. International Journal of Language and Literature 4.1, 21-35.

[2] Al-Alami, S. (2014). Stylistics within EFL/ESL Contexts. US-China Foreign Language 12, 642-649.

[3] Al-Alami, S. (2013). Utilising Fiction to Promote English Language Acquisition. United Kingdom: Cambridge Scholars Publishing.

[4] Busse, B. and McIntyre, D. (2010). Language, Literature and Stylistics. In D. McIntyre and B. Busse (eds.) Language and Literature. United Kingdom: Palgrave Macmillan, 3-14.

[5] Clark, U. (2007). Stylistics and Detective Case Study. In G. Watson, and S. Zyngier (eds.) Literature and Stylistics for Language Learners: Theory and Practice. United Kingdom: Palgrave Macmillan, 60-78.

[6] Cook, G. (2003). Applied Linguistics. United Kingdom: Oxford University Press.

[7] Crawshaw, R. (1996). The Boundaries of Style and Stylistics. Modern Language Review 91.2, 273-280.

[8] Durant, A. et al. (2000). Ways of Reading: Advanced Reading Skills for Students of English Literature (2 ${ }^{\text {nd }}$ edition). London and New York: Routledge.

[9] Egidi, G. and Gerric, R. (2006). Readers' Experiences of Characters' Goals and Actions. Journal of Experimental Psychology: Learning, Memory and Cognition 32.6, 1322-1329.

[10] Fowler, R. (1986) Linguistic Criticism. United Kingdom: Oxford University Press.

[11] Fowler, R. (1977). Linguistics and the Novel. United Kingdom: Methuen.

[12] Gross, J. B. (1993). A Telling Side of Narration: Direct Discourse and French Women Writers. The French Review 66.3, 401411.

[13] Harding, D.W. (2007). The Supposed Letter Form of Sense and Sensibility. Notes and Queries 40.4, 464-466.

[14] Hardy, D. (2005). Towards a Typology of Narrative Gaps: Knowledge Gapping in Flannery O'Connor's Fiction. Language and Literature 14.4, 363-375.

[15] Hardy, D. (2003). Narrating Knowledge in Flannery O'Connor's Fiction. United States of America: University of South Carolina Press.

[16] Jacobus, L. (1989). Writing as Thinking. United Kingdom: Macmillan.

[17] Kvantaliani, N. (2014). Variations and Effects of Speech and Thought Presentation Categories on the Basis of Short Stories by Contemporary Writers in English. International Journal of Humanities and Social Sciences 4.8, 30-36.

[18] Leech, G. N. and Short, M. H. (1981). Style in Fiction. United Kingdom: Longman.

[19] Leech, G. (2010). Analyzing Literature through Language: Two Shakespearian Speeches. In D. Mclntyre and B. Busse (eds.) Language and Style. United Kingdom: Palgrave Macmillan, 15-31.

[20] McIntyre, D. (2004). Point of View in Drama: A Socio-Pragmatic Analysis of Dennis Potter's Brimstone and Treacle. Language and Literature 13.2, 139-160.

[21] Morini, M. (2011). Point of View in First-Person Narratives: A Deictic Analysis of David Copperfield. Style 45.4, 598-695.

[22] Murphy, T. P. (2007). Monitored Speech: The 'Equivalence' Relation between Direct and Indirect Speech in Jane Austen and James Joyce. Narrative 15.1, 24-39.

[23] Palmer, F.R. (2003). Modality in English: Theoretical, Descriptive and Typological Issues. In R. Facchinetti, M. Krug, and F.R. Palmer (eds.) Modality in Contemporary English. Germany: Mouton de Gruyter, 1-10.

[24] Prince, G. (1988). The Disnarrated. Style 22, 1-8. 
[25] Rapp, D.N. and Gerrig, R.J. (2006). Predilections for Narrative Outcomes: The Impact of Story Contexts and Reader Preferences. Journal of Memory and Language 54, 54-67.

[26] Semino, E. (2004). Representing Characters' Speech and Thought in Narrative Fiction: A Study of England England by Julian Barnes. Style 38.4, 428-451.

[27] Semino, E. (2002). A Cognitive Approach to Mind Style in Narrative Fiction. In E. Semino and J. Culpeper (eds.) Cognitive Stylistics: Language and Cognition in Text Analysis. Holland: John Benjamin, 95-122.

[28] Semino, E. and Short, M. (2004). Corpus Stylistics: Speech, Writing and Thought Presentation in a Corpus of English Writing. http://bookos-z1.org (accessed 16/8/2016).

[29] Shen, D. (2010). The Stylistics of Narrative Fiction. In D. Mclntyre, and B. Busse (eds.) Language and Style. United Kingdom: Palgrave Macmillan, 225-249.

[30] Short, M. (1996). Exploring the Language of Poems, Plays and Prose. United Kingdom: Longman.

[31] Short, M. and Candlin, C. (1989). Teaching Study Skills for Literature Students. In M. Short (ed.) Reading, Analyzing and Teaching Literature. United Kingdom: Longman, 178-203.

[32] Simpson, P. (2010). Point of View. In D. McIntyre \& B. Busse (eds.) Language and Style. United Kingdom: Palgrave Macmillan, 293-310.

[33] Simpson, P. (2004). Stylistics: A Resource Book for Students. United Kingdom: Routledge.

[34] Simpson, P. (1993). Language, Ideology, and Point of View. United Kingdom: Routledge.

[35] Uspensky, B. (1973). A Poetics of Composition. United States of America: University of California Press.

[36] Vandelanotte, L. (2004). Deixis and Grounding in Speech and Thought Representation. Journal of Pragmatics 36.3, 489-520.

[37] Zyngier, S. et al (2008). Directions in Empirical Literary Studies: In Humour of Willie van Peer. Holland: John Benjamin.

Suhair E. Al-Alami holds a PhD degree in English Applied Linguistics from Aston University, United Kingdom, and another $\mathrm{PhD}$ degree in English Linguistics from Ain Shams University, Egypt. Currently, she works as Assistant Professor at Al Ghurair University, Dubai. Al-Alami has contributed a wide range of research papers to various ranked journals. Moreover, she has served as a co-editor of six publications, and has also reviewed many articles for refereed journals and conferences. Last but not least, AlAlami has received a number of recognition awards and certificates for her research, teaching, professional development, and community service activities. 